\title{
Protein Subunit
}

National Cancer Institute

\section{Source}

National Cancer Institute. Protein Subunit. NCI Thesaurus. Code C118424.

A polypeptide chain that associates with itself or at least one other chain to form a functional protein or protein complex. 